\section{Response: Re: How Evolving United States Payment Models Influence Primary Care and Its Impact on the Quadruple Aim}

To the Editor: We appreciate Dr. Fiscella and Dr. Carroll's amendment to our article and enthusiastically agree with the assertion that health equity is an important lens through which to gauge the effectiveness of payment models. While we assessed how these models affected health outcomes broadly, we agree that an important addition would be to specifically examine their impact on health equity.

As Dr. Fiscella and Dr. Carroll note, risk-adjusted (based on social determinants of health in addition to medical determinants) global payments are one potential path toward equity, by ensuring that adequate resources are dedicated to patients with more complex needs and that there is flexibility in funds to meet social needs in addition to medical needs. In our characterization of payment models we have included whether the model includes risk adjustment.

Another consideration relevant to payment models is to include measures of equity in performance metrics. We have raised concerns that models like the MeritBased Incentive Payment System have the potential to widen existing disparities. ${ }^{1}$ There is important work underway to develop measures that adequately assess primary care, including impact on health equity, begun at Starfield Summit III and being continued at the Larry A. Green Center for the Advancement of Primary Health Care for the Public Good.

While primary care has been shown to attenuate health disparities, improved payment for primary care is necessary but not sufficient for achieving health equity. Achieving population health equity goals also requires ensuring access to health care for all, looking further upstream to payment for social services, and systematically addressing structural racism and discrimination.

Stephanie B. Gold, MD

Eugene S. Farley, Jr. Health Policy Center, University of Colorado, Aurora, CO, Brian Park, MD, MPH

Department of Family Medicine, Oregon Health \& Science University, Portland, OR, Andrew Bazemore, MD, MPH

Robert Graham Center for Policy Studies in Family Medicine and Primary Care, Washington, D.C.,

Winston Liaw, MD, MPH

Robert Graham Center for Policy Studies in Family

Medicine and Primary Care, Washington, D.C.,

Family \& Community Medicine, University of Texas

Health Science Center at Houston, Houston, TX

\section{References}

1. Eggleton K, Liaw W, Bazemore A. Impact of gaps in meritbased incentive payment system measures on marginalized populations. Ann Fam Med 2017;15:255-7.

doi: 10.3122/jabfm.2019.01.180293

The above letter was referred to the author of the article in question, who offers the following reply.

\section{Re: If We Don't Ask, They Won't Tell: Screening for Urinary and Fecal Incontinence by Primary Care Providers}

Dear Editor, we read the publication on "If We Don't Ask, They Won't Tell: Screening for Urinary and Fecal Incontinence by Primary Care Providers" with a great interest. ${ }^{1}$ Brown et al. ${ }^{1}$ found that most practitioners screened for urinary incontinence (UI) but not fecal continence (FI). We would like to share ideas on this issue. As noted by Brown et al., the problems about UI and FI are considered possibly shameful to talk among our patients in our setting in Indochina. The history about urination and defecation is rarely given by the patients unless there is a serious clinical problem. Asking for the UI and FI might get denial response or disguised information. Due to the possible taboo, ${ }^{2-3}$ it is suggested that the primary care practitioners should specially focus on the possible hidden problems. Special focus might be given to the elderly group whom the problems are common. Establishing trust is needed and it usually takes time to achieve success. ${ }^{4}$ The primary care nurse might take important role for this activity. ${ }^{4}$ Using a questionnaire of session interview might be considered, and the additional use of laboratory screening to seek for possible hidden problem in urinary and gastrointestinal tract, regardless of compliant or history of UI and FI, is recommended.

Beuy Joob, PhD

Sanitation 1 Medical Academic Center, Bangkok, Thailand

Viroj Wiwanitkit, MD

DY Patil University, Pune, India and Ayobabalola University, Nigeria

\section{References}

1. Brown HW, Guan W, Schmuhl NB, Smith PD, Whitehead ME, Rogers RG. If we don't ask, they won't tell: screening for urinary and fecal incontinence by primary care providers. J Am Board Fam Med 2018;31:774-82.

2. Papenkordt U. Pflege $Z$. The urinary and fecal incontinence taboo topic: counseled well, secure travel. Pflege 2011;64: 329-33.

3. Pearce L. Time to break the continence taboo. Nurs Stand 2016;30:24-5.

4. Gray M, Burns SM. Continence management. Crit Care Nurs Clin North Am 1996;8:29-38.

doi: 10.3122/jabfm.2019.01.180267

\section{Response: Re: If We Don't Ask, They Won't Tell: Screening for Urinary and Fecal Incontinence by Primary Care Providers}

The above letter was referred to the author of the article in question, who offers the following reply.

To the Authors: We are thrilled that you took the time to read and comment on our article. Thank you for offering a cultural perspective on the stigma surrounding urinary and fecal incontinence. Importantly, you note that pa- 